\title{
Reinforcement of Polyester with Renewable Ramie Fibers
}

\author{
Noan Tonini Simonassi ${ }^{a}{ }^{*}$, Artur Camposo Pereira ${ }^{a}$, Sergio Neves Monteiro ${ }^{a}$, Frederico Muylaert
}

\author{
Margem $^{b}$, Rubén Jesus Sánchez Rodríguez, Janine Feitosa de Deus ${ }^{b}$, Carlos Mauricio Fontes
}

Vieira ${ }^{b}$, Jaroslaw Drelich

\author{
${ }^{a}$ Department of Materials Science, Military Institute of Engineering - IME, Praça General Tibúrcio, 80, \\ Praia Vermelha, 22290-270, Urca, Rio de Janeiro, RJ, Brazil \\ ${ }^{b}$ Advanced Materials Laboratory (LAMAV) State University of Northern Rio de Janeiro Darcy Ribeiro - \\ UENF, Av. Alberto Lamego, 2000, Parque California, 28035-200, Campos dos Goitacazes, RJ, Brazil \\ ${ }^{c}$ Department of Materials Science and Engineering, Michigan Technological University, \\ Houghton, MI, USA
}

Received: December 12, 2016; Revised: February 22, 2017; Accepted: April 09, 2017

\begin{abstract}
Ramie (Boehmeria nivea) fiber is one of several lignocellulosic fibers with superior strength, but the least investigated, particularly as reinforcement in strong, tough polymeric composites. This paper presents mechanical properties for polyester reinforced with aligned ramie fibers up to $30 \%$ by volume. It was found that adding $30 \mathrm{vol} \%$ of ramie fibers increases the flexural strength of polyester about three times $(212 \pm 12 \mathrm{MPa}$ vs. $63 \pm 7 \mathrm{MPa})$ and tensile strength by a factor of two $(89 \pm 9$ MPa vs. $53 \pm 3 \mathrm{MPa}$ ). Polyester-ramie fiber composites also displayed a significant improvement in toughness. The impact energy values, as measured by Charpy and Izod impact tests, increased nearly two orders of magnitude for $30 \mathrm{vol} \%$ ramie fiber composite as compared to neat polyester. Additionally, fractographic studies revealed reasonable wetting of fibers by the polyester resin, and FTIR analysis confirmed a hydrophilic nature of ramie fibers. In spite of weak adhesion between hydrophilic fibers and hydrophobic matrix, composites of improved strength and toughness were demonstrated in this study. Limited fiber-matrix adhesion was reflected in preferential longitudinal propagation of cracks along the fiber/polyester interfaces, indicating also that most of the fracture area is associated with the fiber surface.
\end{abstract}

Keywords: Ramie fiber, Biofibers, Polyester, Thermal Molding, Flexural Properties, Fracture, Impact Strength, Toughness

\section{Introduction}

Natural fibers extracted from plants, generally termed as 'lignocellulosic fibers', are presently considered engineering materials ${ }^{1}$ that also constitute an environmentally appropriate alternative to replace more expensive, non-recyclable and energy-intensive synthetic fibers ${ }^{2,3}$. This is due to the recognition of various attractive attributes such as abundance, availability, renewability and low cost, together with increasing environmental concerns for the use of synthetic nonrenewable fibers. As a consequence, several lignocellulosic fibers have been investigated in recent years and are already being applied as reinforcement for polymer composites, owing to the attributes listed above $e^{4-15}$. Other attractive features of lignocellulosic fibers include reduced damage to tooling and molding equipment, as well as relatively better surface finishes and lower abrasiveness of composite part surfaces ${ }^{11}$.

Lignocellulosic fibers are typical of tropical regions and, in principle, their application in industrialized composites

* e-mail: noantoninisimonassi@gmail.com would represent job opportunities and income for developing countries in Africa, South Asia and Latin America ${ }^{16}$. In fact, composites reinforced with coconut, sisal, jute, and hemp are already on the market as substitutes for more common fiberglass automobile components ${ }^{17-19}$. Alternative reinforcements have found use in components such as interior panels and seat cushions made of fiberglass or polymeric foams ${ }^{20}$. Among the lignocellulosic fibers with potential as composite reinforcement, that extracted from the stem of ramie (Boehmeria nivea), and shown in Fig. 1 is now investigated. The tensile strength of non-selected ramie fibers with diameters $60-140 \mu \mathrm{m}$ varies from 400 to 938 $\mathrm{MPa}^{7,13,16}$, and is comparable to those of other strong natural fibers such as flax, jute, sisal, kenaf, hemp, pineapple and curaua ${ }^{13,16}$. Selected smaller diameter $(25 \mu \mathrm{m})$ of ramie fibers demonstrated tensile strength of about $1,500 \mathrm{MPa}^{1}$.

Despite attractive strength properties and numerous studies on reinforced composites ${ }^{21-43}$, little has been reported on the use of ramie fibers in polyester composites. These limited ramie/polyester composite studies were carried out on Brazilian ramie fibers, mostly by the authors' group ${ }^{22,38,39,41,43}$. 


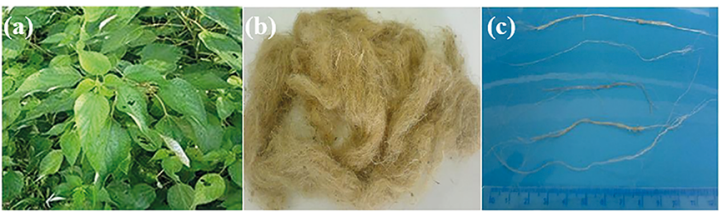

Figure 1. The typical ramie plant (a), bunch of ramie fibers (b) and separated ramie fibers (c).

Indeed, Brazil was the third world producer of the ramie fiber during 1990s, with about 10 thousand tons annual production, primarily for use in textiles ${ }^{16}$. However, the ramie plant cultivation and fiber processing have been declining in Brazil in the past decade. A possibility to revitalize the production of ramie fibers could be related to their use in new industrial composite materials. With favorable mechanical properties, ramie fiber composites are attractive structural materials for doors, panels, and furniture. They could also compete with other traditional lignocellulosic fiber composites for automobile components ${ }^{17-20}$.

Novel polyester composites reinforced with ramie fibers were formulated in the present work and characterized for their flexural, tensile and impact properties. From 10 to $30 \mathrm{vol} \%$ of aligned fibers were added to polyester without involvement of compatibilizing agents or treatment of the fiber surfaces that would increase costs. The composites were formulated using press molding technology. Fiber infrared analysis and composites SEM fractographs disclosed the effectiveness of the fiber/matrix interaction.

\section{Experimental}

\subsection{Materials}

Ramie fibers used in this study were received from Brazilian firm SISALSUL (São Paulo, Brazil) which commercializes various natural fibers. These fibers were minimally processed with only water cleaning and air drying at room temperature. Moisture content was determined, after drying at $60^{\circ} \mathrm{C}$ in a stove, to be around $8 \mathrm{wt} \%$. The matrix polymer used was a fluid orthophthalic polyester resin with methyl-ethyl-ketone as catalyst provided by Dow Chemical and supplied by Resinpoxy, Brazil.

\subsection{Methods}

The characteristics of the lot of ramie fibers used in this investigation were statistically evaluated based on the analysis of 100 ramie fibers. Each ramie fiber had its length and diameter measured. The diameter was measured at seven points by a profile projector and then rotated 90 degrees to a second set of measurements, assuming the fibers have approximately circular cross section. Double measurements were taken at each point. The fibers were then weighed on a precise balance. Using the Weibull method the mean density of ramie fibers was determined.

Composites with continuous and aligned ramie fibers $(10,20$ and $30 \mathrm{vol} \%)$ were formulated by press molding in a DIPAMAK (Model 30T) hydraulic press. Fibers were impregnated with fluid orthophthalic polyester resin and $0.5 \mathrm{wt} \%$ methyl-ethyl-ketone catalyst. The mixture was set to cure at room temperature for $24 \mathrm{~h}$ inside a $152 \times 122 \mathrm{x}$ $10 \mathrm{~mm}$ rectangular mold under $0.53 \mathrm{MPa}$ of pressure. The ramie fibers were aligned along the $122 \mathrm{~mm}$ width of the mold. Six rectangular $122 \times 25 \times 10 \mathrm{~mm}$ flexure specimens were cut from each composite plate after $24 \mathrm{~h}$ curing. These specimens were subjected to room temperature (RT) three points bend tests, according to ASTM D790 standard, in an Instron machine (Model 5582) with load cell of $1 \mathrm{kN}$ at a strain rate of $1.6 \times 10^{-2} \mathrm{~s}^{-1}$ and a span-to-depth ratio of 9 .

Tensile test specimens were prepared individually by arranging the fibers in silicone dogbone-shaped mold with $5.8 \times 4.5 \mathrm{~mm}$ reduced cross section and $35 \mathrm{~mm}$ length. The volume fraction up to $30 \mathrm{vol} . \%$ ramie fibers were aligned continuously along the mold. The resin was poured over the fibers inside the mold and cured for 24 hours at RT. Seven specimens for each amount of ramie fibers were prepared for the test. These specimens were subjected to RT tensile test in an INSTRON machine (Model 5582) with load cell of $1 \mathrm{kN}$ at a strain rate of $10^{-2} \mathrm{~s}^{-1}$.

For Charpy impact tests, following the ASTM D6110 standard, notched specimens $(122 \times 12.7 \times 10 \mathrm{~mm})$ were cut from the composite plates along the direction of alignment of the fibers. The notch with $2.54 \mathrm{~mm}$ depth, angle of $45^{\circ}$ and a tip curvature radius of 0.25 was machined according to DIN 847 norm. For each condition, 14 specimens were tested to ensure statistical validation. The specimens were RT impact tested using a Charpy hammer pendulum in an EMIC machine (model AIC). The impact energy was obtained with a $2.7 \mathrm{~J}$ hammer for the pure polyester specimens and with a $5.4 \mathrm{~J}$ hammer for their ramie fiber composites.

In the Izod impact tests, also following the ASTM D256 standard, notched specimens $(61 \times 12.7 \times 10 \mathrm{~mm})$ were cut from the composite plates along the direction of alignment of the fibers. For each condition, 14 specimens were tested to ensure statistical validation. The specimens were RT impact tested using an Izod hammer pendulum in the same aforementioned EMIC machine. The impact energy was obtained with a $2.7 \mathrm{~J}$ hammer for the pure polyester and $5.4 \mathrm{~J}$ for their ramie fiber composites.

The Fourier Transform Infrared (FTIR) spectrum of ramie fibers was obtained using a Prestige 21 SHIMADZU spectrometer. Individual ramie fibers, and fractured specimens of pure matrix and their composites were imaged using a JEOL scanning electron microscope (Model JSM-6460 LV) operating at either 10 or $15 \mathrm{kV}$. 


\section{Results and Discussion}

\subsection{Density and Size Distribution}

The average density of the ramie fiber used was found to be $1.49 \pm 0.11 \mathrm{~g} / \mathrm{cm}^{3}$, which agrees with reported $1.5 \mathrm{~g} / \mathrm{cm}^{3}{ }^{16}$. The distribution of length and diameter for a range of statistical groups is shown in Fig. 2. A comparison between the average length of the ramie fibers in this work $(\mathrm{L}=158 \pm 69 \mathrm{~mm})$ with its critical length $\ell_{\mathrm{c}}=1.6 \mathrm{~mm}$, obtained from pullout tests $^{39}$ indicates that these fibers should be considered as continuous $\left(L>15 \ell_{c}\right){ }^{44}$ for composite reinforcement. Since the fibers used are much longer than the critical length, in all the following discussions, they are referred to as 'long'.

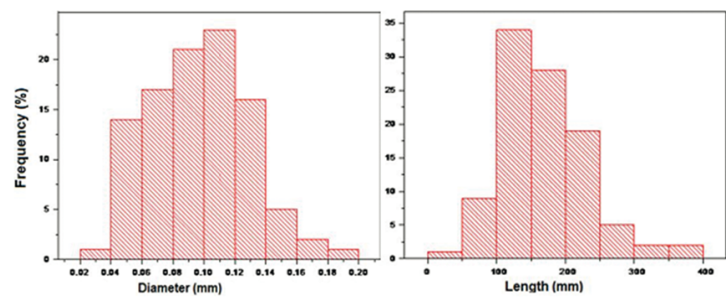

Figure 2. Statistical distribution of length and diameter of the lot of ramie fibers used in this work.

\subsection{Ramie Fiber FTIR}

Figure 3 shows the FTIR transmittance spectrum of the investigated Brazilian ramie fiber. This spectrum is very similar to that reported by Garside and Wyeth ${ }^{45}$ for a distinct ramie fiber (the origin of that fiber was not disclosed). The prominent absorbance band around $3,400 \mathrm{~cm}^{-1}$ in Fig. 3 can be assigned to $\mathrm{OH}$ stretching and associated with adsorbed water on the fiber surface. Other bands, such as those at $1740,1630,1050$ and $620 \mathrm{~cm}^{-1}$ can be related to $\mathrm{C}=\mathrm{O}, \mathrm{C}-\mathrm{O}$, and $\mathrm{C}-\mathrm{H}$ stretching associated with aliphatic, aromatic and acid constituents of the fiber lignin and waxes ${ }^{45}$. Bands in Fig. 3 indicate a strong tendency of the ramie fiber to retain water as well as an active participation of lignin and waxes in possible surface interactions. These results suggest a predominantly hydrophilic nature and a difficulty of ramie fiber adhesion onto hydrophobic polyester. Consequently, a weak ramie fiber/polyester matrix interface is expected.

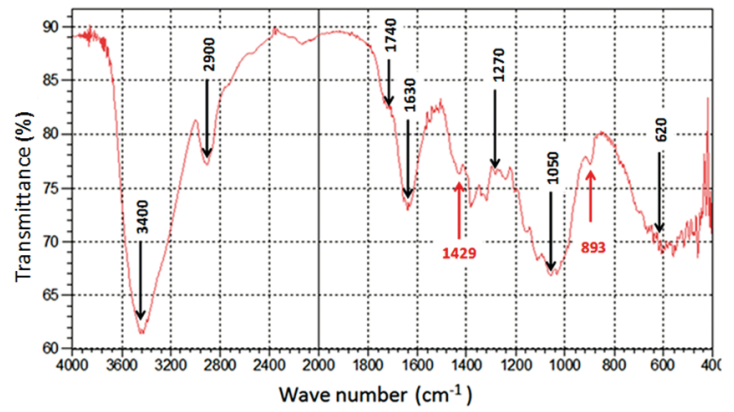

Figure 3. FTIR spectrum of the ramie fiber.
Figure 4 schematically illustrates a suggested model for the molecular structures at the ramie fiber surface facing a polyester macromolecule in the matrix. Not only the adsorbed water on the fiber surface but also the molecular structures of the cellulose, lignin and wax are not able to establish effective bonds with the polyester. In fact, strongly polarized cellulose fibers are inherently incompatible with hydrophobic polymers ${ }^{46}$. Interaction at the fiber/matrix interface in Fig. 4 would be mainly accomplished by van der Waals forces, with some possibility of hydrogen bonding between $\mathrm{OH}$ groups of ramie surface and $\mathrm{C}=\mathrm{O}$ groups of polyester. Thus, a relatively weak interfacial shear stress is to be expected between the ramie fiber and the polyester matrix ${ }^{12,36}$. As further discussed, the weak interactions do not exclude from formulation of ramie fiber/polyester composites with improved strength and toughness.
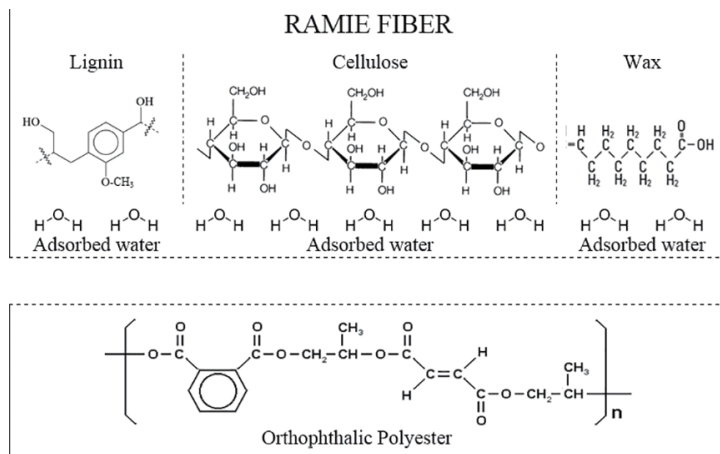

COMPOSITE MATRIX

Figure 4. Schematic model of the molecular structure at ramie fiber/ polyester matrix interface.

\subsection{Mechanical properties}

Figure 5 shows the variation of the flexural strength of the polyester composites, together with snapshots of broken specimens. Within the precision bars (standard deviation) the flexural strength increased exponentially from $63 \pm 7 \mathrm{MPa}$ for neat polyester to $212 \pm 12 \mathrm{MPa}$ for the $30 \mathrm{vol} \% \mathrm{ramie}$ fiber polyester composite, Fig. 5(a). The research results with other lignocellulosic fibers such as jute ${ }^{47}$, piassava ${ }^{48}$ and curaua ${ }^{22}$ also demonstrated improved flexural strength of formulated polymeric composites.

The significant improvement in flexural strength can be explained on the basis of the fiber-matrix interaction and the rupture behavior, common for polymers reinforced with fibers. For the pure polyester, fracture in flexure occurred by transverse brittle rupture at the center region of the specimen where the test machine compressed the specimen. For the ramie fiber composite, though the rupture was also transverse, Fig. 5(b), the long fibers acted as an obstacle for crack propagation through the polyester matrix, resulting in increased resistance to rupture. The effort to break the composite forced the relatively weak fiber/matrix interface to 


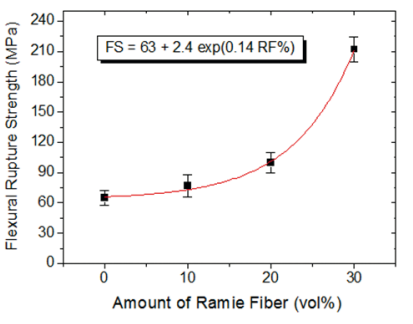

(a)

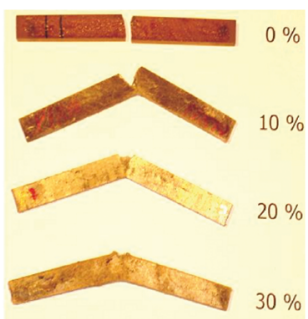

(b)
Figure 5. Variation of the flexural strength (FS) with ramie fiber content (RF\%) in polyester matrix (a) and the macrostructure appearance of the flexural specimens (b).

fail. The rupture may not necessarily nucleate at the center, since much higher fiber/matrix interface area tend to allow cracks to nucleate at interfaces and then propagate between the fiber surface and the polyester matrix. This contributes to an extensive bending deflection and unbroken specimens, Fig. 5(b), regardless of machine crosshead displacement. Such a scenario, characteristic to many fiber-based composites, is supported by fractographs of the pure matrix and the composites.

Figure 6(a) shows the typical fracture surface of a transverse rupture in pure polyester, revealing brittle fracture with some defects. In ramie fiber composites, the transversally fractured polyester matrix with embedded fibers and voids corresponding to fiber pull-out can be seen in Fig. 7(a). Figure 8(a) is a higher magnification of Fig. 7(a), revealing discontinuous interface between the ramie fiber and the polyester matrix. In fact, most of the interfaces presented evidence of debonding in the form of a separation of the fiber surface from the polyester matrix. This can be certainly attributed to the low interfacial shear stress of $6.2 \pm 2.3 \mathrm{MPa}$ found for this type of composite ${ }^{39}$. A weak ramie fiber/ polyester matrix interface is also supported by the FTIR spectrum discussed in Section 3.2. The large difference with respect to the fractures in the 0 and $30 \mathrm{vol} \%$ fiber composites is the greater participation of the fiber surface in the process of rupture. This is associated with a larger area of rupture, running parallel to the direction of fiber alignment, as well as a higher absorbed mechanical energy.

Figure 9 presents the variation in the tensile strength of the polyester composites containing from 0 to $30 \mathrm{vol} \%$ of ramie fiber, along with a photograph of the ruptured specimens. The tensile strength increased from $53 \pm 4 \mathrm{MPa}$ (0 vol\%) to $89 \pm 9 \mathrm{MPa}$ (30 vol\%), reflecting a similar exponential behavior as the flexural strength. Indeed, in the case of neat polyester, fracture occurred by transverse brittle rupture at the center point. The rupture is also transverse in the composites, with fiber acting as an obstacle for crack propagation through the matrix. This is supported by fractographic analysis. Figure 6(b) shows typical transverse surface of fractured pure polyester specimen. A transverse fracture is particularly distinguishable from Fig. 7(b), showing the matrix with embedded fibers and voids corresponding

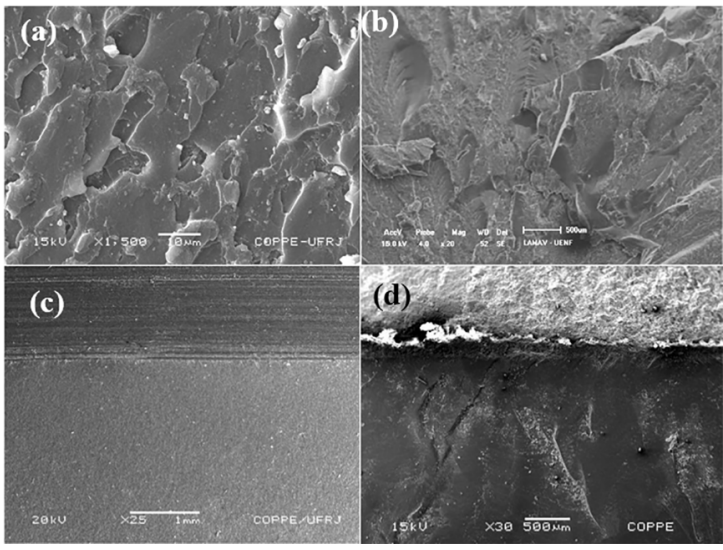

Figure 6. Fractographs of the neat polyester; (a) flexural test (b) tensile test (c) Charpy impact test (d) Izod impact test.

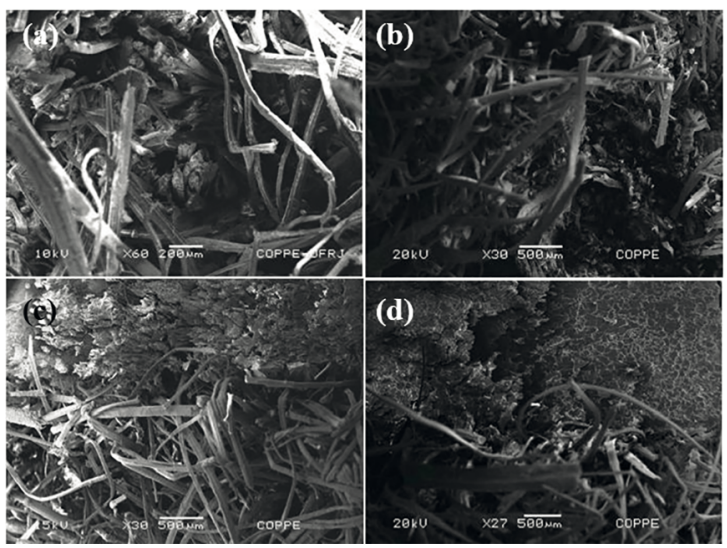

Figure 7. Fractographs of polyester $/ 30 \mathrm{vol} \%$ ramie fiber composite with low magnification: (a) flexural test (b) tensile test (c) Charpy impact test (d) Izod impact test.
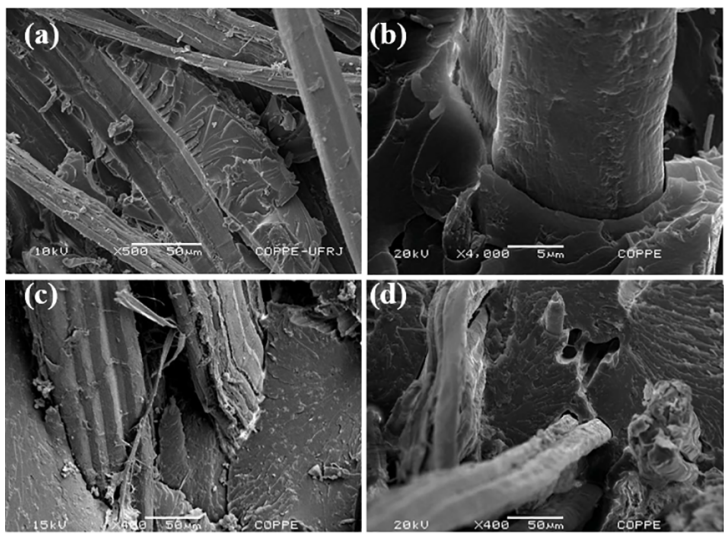

Figure 8. Fractographs of polyester $/ 30 \mathrm{vol} \%$ ramie fiber composite with high magnification; (a) flexural test (b) tensile test (c) Charpy impact test (d) Izod impact test.

to pull out of fibers. A discontinuous interface between the ramie fiber and the matrix is shown in Fig. 8(b), presenting evidence of debonding in the form of a separation of the fiber surface from the polyester matrix. This is expected due to the already mentioned low interfacial shear stress found for this type of composite ${ }^{39}$. 


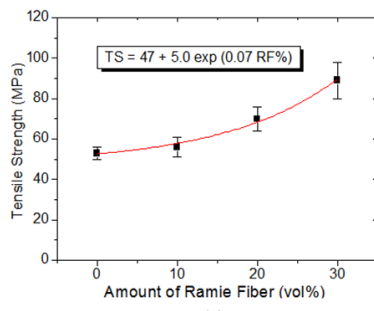

(a)

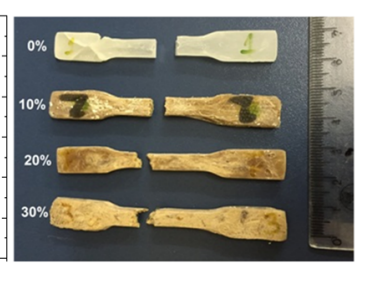

(b)

Figure 9. Variation of the tensile strength (TS) with ramie fiber content $(\mathrm{RF} \%)$ in polyester matrix (a) and the macrostructure appearance of the tensile specimens (b).

It is also important to discuss the implications of the rupture modes to the mechanical response of both flexure and tensile tests. The rupture that initiates inside the polyester matrix propagates transversally to the fiber alignment. The arrest of this initial transverse rupture by the ramie fibers, Fig. 7(b), corresponds to a mechanism of effective reinforcement. This fracture mode allows an improvement in the composite flexural and tensile strengths. Additionally, a rupture that initiates at the fiber/matrix interface propagates longitudinally between the fiber surface and the polyester matrix, Fig. 8(b), corresponding to a mechanism of higher absorbed mechanical energy ${ }^{49}$. This longitudinal rupture mode also causes reinforcement to the composite. The combined action of both modes provides an exponential improvement, as revealed by the observed results for flexure, Fig. 5(a), and tensile, Fig. 9(a), tests. In flexure tests, a longitudinal rupture markedly improves the deformation, measured by the total bending deflection at rupture. In fact, the $30 \mathrm{vol} \%$ of fiber composite specimens ,Fig. 5(b), did not break despite the extension of deformation.

\subsection{Impact Properties}

Figure 10 shows the variation of the Izod impact energy for pure polyester as well as ramie fiber/ polyester matrix composites. The ramie fiber incorporation into the polyester matrix significantly improved the impact toughness of the composite. Within the standard deviation, similar to the flexural and tensile strengths, this improvement can be considered as an exponential function with respect to the amount of ramie fiber. The Izod impact energy value $(\sim 0.59 \mathrm{~kJ} / \mathrm{m})$ increased 39 times for $30 \mathrm{vol} \%$ ramie fiber composite as compared to the pure polyester $(\sim 0.015 \mathrm{~kJ} / \mathrm{m})$. The relatively high variation in impact energy values, given by the standard deviation associated with the higher fiber percentage points in Fig. 10, is a well-known heterogeneous characteristic of the lignocellulosic fibers ${ }^{1-16}$.

The values shown in Fig. 10 are significantly above those reported in the literature for other lignocellulosic fiber-polyester composites tested at low velocity impact ${ }^{50}$ and in standard Izod impact tests ${ }^{51,52}$. Indeed, reinforced with $40 \mathrm{vol} \%$ of long and aligned coir fibers, the Izod impact

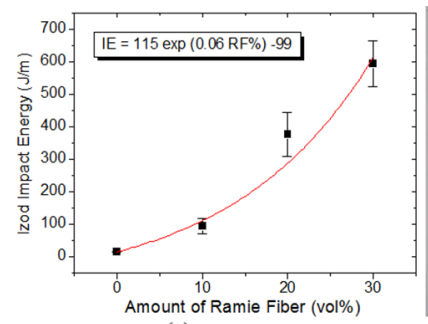

(a)

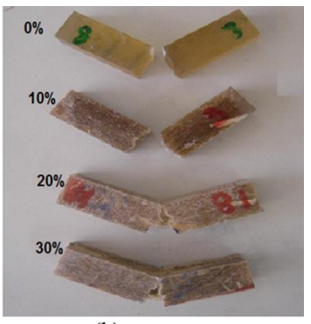

(b)
Figure 10. Variation of Izod impact (IE) energy with ramie fiber content (RF\%) in polyester matrix (a) and the macrostructure appearance of the impact specimens (b).

energy of the composite increased 8 times that of the neat polyester ${ }^{51}$. With $10 \mathrm{wt} \%$ of weaves of peach palm fibers, the increase was 2.6 times the neat polyester impact energy ${ }^{52}$.

The reinforcement of a polymeric matrix with both synthetic $^{53}$ and natural ${ }^{13,50,51}$ fibers are known to increase the impact toughness of the composite. Table 1 compares values of Izod impact energy of polymeric composites with different natural fibers ${ }^{51,54}$. The use of long and aligned ramie fibers resulted in significantly higher impact toughness than those reported $^{54}$ for polypropylene composites reinforced with $50 \mathrm{vol} \%$ of short cut and randomly oriented lignocellulosic fibers. Higher impact resistance of the polyester compared to that of polypropylene matrix could be one of the reasons for the superior performance of the composites studied in this work. Long and aligned ramie fiber reinforced polyester composites are probably the main reason, which results in the toughest among the category of natural fiber polymer composites reported so far.

Figure 11 shows the variation of the Charpy impact energy for polyester and composites. The ramie fiber incorporation into the polyester matrix significantly improved the impact toughness of the composite. Within the standard deviation, this improvement can also be considered as an exponential function with respect to the amount of ramie fiber added. The impact energy value recorded for $30 \mathrm{vol} \%$ composite $(\sim 1 \mathrm{~kJ} / \mathrm{m})$ is 65 times higher than that for neat polyester $(\sim 0.015 \mathrm{~kJ} / \mathrm{m})$.

The relatively low interface strength between a hydrophilic natural fiber and a hydrophobic polymeric matrix, previously reported ${ }^{39}$ and here discussed in Section 3.2, contributes to an ineffective load transfer from the matrix to a longer fiber. This would result in relatively greater fracture surface and higher impact energy needed for the rupture ${ }^{49}$. Another factor is the flexural compliance of a long fiber during the impact test, as discussed below.

The incorporation of long and aligned ramie fibers results in a marked change with respect to neat polyester ( $0 \%$ fiber), in which a totally transverse rupture occurs. Even with $10 \mathrm{vol} \%$ of fiber, the rupture is no longer completely transverse, as evident in Figs. 10(b) and 11(b). This indicates that the cracks nucleated at the notch will initially propagate transversally through the polyester matrix, as expected in a 
Table 1. Impact toughness of polymeric composites reinforced with natural fibers.

\begin{tabular}{lcccc}
\hline Composite & Fiber Content (vol\%) & Fiber Condition in the Composite & $\begin{array}{c}\text { Izod Impact } \\
\text { Toughness (J/m) }\end{array}$ & Reference \\
\hline Ramie/polyester & 30 & Long and aligned & 594 & Present work \\
Jute/Polypropylene & 50 & Short-cut randomly oriented & 39 & (Leao et al. 1998) \\
Sisal/ Polypropylene & 50 & Short-cut randomly oriented & 51 & ibid \\
Flax/ Polypropylene & 50 & Short-cut randomly oriented & 38 & ibid \\
Wood/ Polypropylene & 50 & Short-cut randomly oriented & 28 & ibid \\
Curaua/ Polypropylene & 50 & Short-cut randomly oriented & 54 & ibid \\
Coir/ Polypropylene & 50 & Short-cut randomly oriented & 46 & ibid \\
Coir/polyester & 40 & Long and aligned & 121 & (Monteiro et al. 2008) \\
\hline
\end{tabular}

* Present work

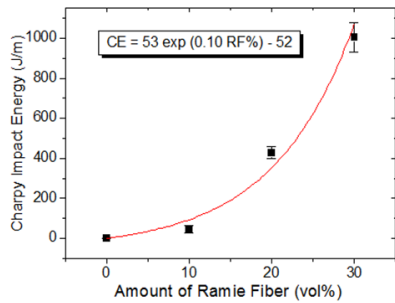

(a)

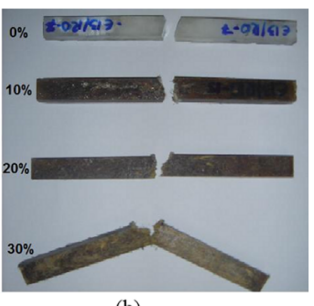

(b)
Figure 11. Variation of Charpy impact energy (CE) with ramie fiber content $(\mathrm{RF} \%)$ in polyester matrix (a) and the macrostructure appearance of the impact specimens (b).

monolithic polymer. However, when the crack front reaches a fiber, the rupture proceeds through the fiber/matrix interface. As a consequence, after the Izod, Fig. 10, or Charpy, Fig. 11, hammer hits the specimen, some long fibers are pulled out from the matrix but, owing to their compliance, do not break but simply bend. In fact, few totally ruptured fibers were observed in the composites containing fibers above 20 vol\%. For these amounts of long and aligned ramie fibers, part of the specimen was bent enough to allow the hammer to continue its trajectory, either by leaving the hit part still attached to the fixed part of the Izod specimen, Fig. 10(b), or carrying away the full Charpy specimen, Fig. 11(b), without complete separation. The value of the impact toughness in this case cannot be compared with others in which the specimen is totally split apart.

The fact that a specimen is not completely separated into two parts underestimates the impact toughness. In other words, had all the fibers been broken, the absorbed impact energy would have been still higher. The mechanism discussed above is better understood by the fractographic studies carried out on the tested samples. Figures 6(c) and $6(d)$ show the fracture surface of a pure polyester ( $0 \%$ fiber) specimen. The upper layer with distinct shades of gray in the fractographs corresponds to the notch in the specimen, revealing the horizontal marks from machining. The smoother and dissimilar gray layer underneath corresponds to the transversal fracture surface. Observed fracture suggests that a single crack was responsible for the rupture. The roughness is likely associated with voids and imperfections introduced during the matrix processing.

Figures 7(c) and 7(d) show details of the Charpy and Izod impact fracture surface of $30 \mathrm{vol} \%$ ramie fiber composite. They reveal a reasonable penetration (wetting) of polyester in between the fibers and the direction of preferential propagation of cracks. Some fibers were pulled out from the matrix and some broken fibers can also be seen. By contrast, the part of the specimen in which the preferential rupture occurred, longitudinally through the fiber/matrix interface, revealed that most of the fracture area is associated with the fiber surface. This behavior corroborates the rupture mechanism of cracks that propagate preferentially between the fiber surface and the polyester matrix, and could be due to low interfacial strength ${ }^{39,49}$. The greater fracture area seen in Figs. 8(c) and 8(d) associated with long and aligned fibers acting as reinforcement for the composite justify the higher absorbed impact energy.

\section{Final Comment on Fiber/Matrix Interactions}

Based on the results presented in Figs. 3 to 11, it should be emphasized that a weak interaction between the polyester matrix and the strong ramie fibers acts as an effective mechanism to propagate longitudinal cracks along the fiber/matrix interface. This favors not only the pullout of some fibers but also the integrity of the composite until the complete rupture and/or pull-out of the long ramie fibers. The relatively high tensile strength of these fibers ${ }^{1,39}$ prevents an earlier collapse of the composite structure, as depicted in Figs. 5(b), 9(b), 10(b) and 11(b) for fiber amounts above $20 \mathrm{vol} \%$. Moreover, the combination of weak fiber matrix interface, which promotes longitudinal fracture, and a high strength reinforcing fiber contributes significantly to improve the composite flexural, Fig. 5(a), and tensile, Fig. 9(a), strengths as well as its impact resistance, Fig. 10(a) and Fig.11(a). Indeed, for the first time, it is shown that this combination results in exponential strength and toughness improvements shown for the first time in polyester composites. 


\section{Conclusion}

Natural fibers from the ramie plant (Boehmeria nivea) were used in this study as reinforcement to polyester. Composites with up to $30 \mathrm{vol} \%$ of ramie fibers were formulated using a mold pressing technology. Flexural and tensile strengths as well as impact energies of formulated composites were measured. Fracture mechanisms were analyzed based on macroscopic view of broken specimens and SEM fractographs. The following conclusions were reached:

- Brazilian ramie fibers can be successfully incorporated as reinforcement to polyester composites without the use of surface modifying agents. Beyond 30 vol\% fiber, the wetting with polyester becomes difficult and properties are impaired.

- The reinforcement of polyester with $30 \mathrm{vol} \%$ of ramie fibers increased its flexural strength about three times, from $63 \pm 7 \mathrm{MPa}$ to $212 \pm 12 \mathrm{MPa}$, and tensile strength nearly two times, from $53 \pm 4$ $\mathrm{MPa}$ to $89 \pm 9 \mathrm{MPa}$.

- $\quad$ Formulated composite also displayed a significant exponential improvement in toughness. The Charpy impact energy $(\sim 1 \mathrm{~kJ} / \mathrm{m})$ and Izod impact energy $(\sim 0.59 \mathrm{~kJ} / \mathrm{m})$ values increased two orders of magnitude for $30 \mathrm{vol} \%$ ramie fiber composite as compared to polyester $(\sim 0.015 \mathrm{~kJ} / \mathrm{m})$.

- The fractographic studies revealed that the rupture in composites initiates and propagates transversally (perpendicular to the fiber alignment) through the matrix. Ramie fibers act as obstacles to crack propagation, resulting in an effective improvement of the strength. Poor fiber-polyester adhesion is responsible for a longitudinal propagation of cracks throughout the interface, which generates larger rupture areas, as compared to a transverse fracture and increases the energy absorbed upon impact.

- Polyester composites with fiber content above 20 vol\% showed incomplete rupture of the specimen owing to the bend flexibility, i.e., flexural compliance, of the ramie fibers. The combination of weak fiber/ matrix interface with the strong ramie fiber results in exponential strength and toughness improvements for the polyester composites.

\section{Acknowledgments}

The authors would like to acknowledge CNPq and CAPES for the financial support received for this study. JWD thanks FAPERJ for the visitor researcher grant that funded his visit in Brazil. The authors also express appreciation to PEMM/ COPPE/UFRJ for the use of the SEM microscope. JWD also appreciate addicting corrections suggested by Patrick Bowen

\section{References}

1. Monteiro SN, Lopes FPD, Barbosa AP, Bevitori AB, Da Silva ILA, Da Costa LL. Natural Lignocellulosic Fibers as Engineering Materials-An Overview. Metallurgical and Materials Transactions A. 2011;42(10):2963-2974.

2. Wambua P, Ivens J, Verpoest I. Natural fibres: can they replace glass in fibre reinforced plastics? Composites Science and Technology. 2003;63(9):1259-1264.

3. Joshi SV, Drzal LT, Mohanty AK, Arora S. Are natural fiber composites environmentally superior to glass fiber reinforced composites? Composites Part A: Applied Science and Manufacturing. 2004;35(3):371-376.

4. Mohanty AK, Misra M, Hinrichsen G. Biofibres, biodegradable polymers and biocomposites: An overview. Macromolecular Materials and Engineering. 2000;276-277(1):1-24.

5. Eichhorn SJ, Baillie CA, Zafeiropoulos N, Mwaikambo LY, Ansell MP, Dufresne A, et al. Review: Current international research into cellulosic fibres and composites. Journal of Materials Science. 2001;36(9):2107-2131.

6. Mohanty AK, Misra M, Drzal LT. Sustainable Bio-Composites from Renewable Resources: Opportunities and Challenges in the Green Materials World. Journal of Polymers and the Environment. 2002;10(1):19-26.

7. Netravali AN, Chabba S. Composites get greener. Materials Today. 2003;6(4):22-29.

8. Crocker J. Natural materials innovative natural composites. Materials Technology. 2008;23(3):174-178.

9. John MJ, Thomas S. Biofibres and biocomposites. Carbohydrate Polymers. 2008;71(3):343-364.

10. Satyanarayana KG, Arizaga GGC, Wypych F. Biodegradable composites based on lignocellulosic fibers-An overview. Progress in Polymer Science. 2009;34(9):982-1021.

11. Monteiro SN, Lopes FPD, Ferreira AS, Nascimento DCO. Natural-fiber polymer-matrix composites: Cheaper, tougher, and environmentally friendly. JOM. 2009;61(1):17-22.

12. Kalia S, Kaith BS, Kaur I, eds. Cellulose Fibers: Bio and Nano-Polymer Composites. New York: Springer; 2011.

13. Faruk O, Bledzki AK, Fink HP, Sain M. Biocomposites reinforced with natural fibers: 2000-2010. Progress in Polymer Science. 2012;37(11):1552-1596.

14. Thakur VK, Thakur MK. Processing and characterization of natural cellulose fibers/thermoset polymer composites. Carbohydrate Polymers. 2014;109:102-117.

15. Güven O, Monteiro SN, Moura EAB, Drelich JW. Re-Emerging Field of Lignocellulosic Fiber - Polymer Composites and Ionizing Radiation Technology in their Formulation. Polimer Reviews. 2016;56(4):702-736.

16. Satyanarayana KG, Guimarães JL, Wypych F. Studies on lignocellulosic fibers of Brazil. Part I: Source, production, morphology, properties and applications. Composites Part a-Applied Science and Manufacturing. 2007;38(7):1694-1709. 
17. Marsh G. Next step for automotive materials. Materials Today. 2003;6(4):36-43.

18. Holbery J, Houston D. Natural-fiber-reinforced polymer composites applications in automotive applications. JOM. 2006;58(11):80-86.

19. Zah R, Hischier R, Leão AL, Braun I. Curaua fibers in the automobile industry - a sustainability assessment. Journal of Cleaner Production. 2007;15(11-12):1032-1040.

20. Mercedes-Benz. 2014. Available from: $<\mathrm{http}: / / \mathrm{www}$. mercedesbenz.com.br>. Access in: 15/11/2014.

21. Li SH, Zhou BL, Zeng QY, Bao XR. A new kind of super-hybrid composite-material for civil use - ramie fibre/Al. Composites. 1994;25(3):225-228.

22. Paiva Júnior CZ, de Carvalho LH, Fonseca VM, Monteiro SN, d'Almeida JRM. Analysis of the tensile strength of polyester/ hybrid ramie-cotton fabric composites. Polymer Testing. 2004;23(2):131-135.

23. Lodha P, Netravali AN. Characterization of stearic acid modified soy protein isolate resin and ramie fiber reinforced 'green' composites. Composites Science and Technology. 2005;65(78):1211-1225.

24. Lu YS, Weng LH, Cao DX. Morphological, thermal and mechanical properties of ramie crystallites - reinforced plasticized starch biocomposites. Carbohydrate Polymers. 2006;63(2):198-204.

25. Park JM, Son TQ, Jung JG, Hwang BS. Interfacial evaluation of single Ramie and Kenaf fiber/epoxy resin composites using micromechanical test and nondestructive acoustic emission. Composite Interfaces. 2006;13(2-3):105-129.

26. Nam S, Netravali AN. Green composites. II. Environmentfriendly, biodegradable composites using ramie fibers and soy protein concentrate (SPC) resin. Fibers and Polymers. 2006;7(4):380-388.

27. Lei W, Lei WG, Ren C. Effect of volume fraction of ramie cloth on physical and mechanical properties of ramie cloth/UP resin composite. Transactions of Nonferrous Metals Society of China. 2006;16(Suppl 2):S474-S477.

28. Long CG, He LP, Zhong ZH, Chen SG. Studies on the Polypropylene Composites Reinforced by Ramie Fiber and $\mathrm{K}_{2} \mathrm{Ti}_{6} \mathrm{O}_{13}$ whisker. Research Letters in Materials Science. $2007 ; 1: 87072$.

29. Kishi H, Fujita A. Wood-based epoxy resins and the Ramie fiber reinforced composites. Environmental Engineering and Management Journal. 2008;7(5):517-523.

30. He LP, Tian Y, Wang LL. Study on Ramie Fiber Reinforced Polypropylene Composites (RF-PP) and its Mechanical Properties. Advanced Materials Research. 2008;41-42:313-316.

31. Xu H, Wang LH, Teng CQ, Yu MH. Biodegradable Composites: Ramie Fibre Reinforced PLLA-PCL Composite Prepared by in Situ Polymerization Process. Polymer Bulletin. 2008;61(5):663-670.

32. Müssig J. Cotton Fibre-reinforced Thermosets Versus Ramie Composites: A Comparative Study using Petrochemical- and Agro-based Resins. Journal of Polymers and the Environment. 2008;16(2):94-102.
33. Yu T, Li Y, Ren J. Preparation and properties of short natural fiber reinforced poly(lactic acid) composites. Transactions of Nonferrous Metals Society of China. 2009;19(Suppl 3):S651-S655.

34. Marsyahyo E, Jamasri, Rochardjo HSB, Soekrisno. Preliminary Investigation on Bulletproof Panels Made from Ramie Fiber Reinforced Composites for NIJ Level II, IIA, and IV. Journal of Industrial Textiles. 2009;39(1):13-26.

35. Kumar R, Zhang L. Aligned ramie fiber reinforced arylated soy protein composites with improved properties. Composites Science and Technology. 2009;69(5):555-560.

36. Kalia S, Kaith BS, Kaur I. Pretreatments of natural fibers and their application as reinforcing material in polymer composites-A review. Polymer Engineering and Science. 2009;49(7):1253-1272.

37. Margem FM, Monteiro SN, Bravo Neto J, Rodriguez RJS, Soares BG. The dynamic-mechanical behavior of epoxy matrix composites reinforced with ramie fibers. Matéria (Rio de Janeiro). 2010;15(2):164-171.

38. Monteiro SN, Satayanarayana KG, Lopes FPD. High Strength Natural Fibers for Improved Polymer Matrix Composites. Materials Science Forum. 2010;638-642:961-966.

39. Monteiro SN, Satyanarayana KG, Margem FM, Ferreira AS, Nascimento DCO, Santafé Jr HPG, et al. Interfacial Shear Strength in Lignocellulosic Fibers Incorporated Polymeric Composites. In: Kalia S, Kaith BS, Kaur I, eds. Cellulose Fibers: Bio- and Nano-Polymer Composites. Berlin - Heidelberg: Springer-Verlag; 2011. p. 241-262.

40. Choi HY, Lee JS. Effects of surface treatment of ramie fibers in a ramie/poly(lactic acid) composite. Fibers and Polymers. 2012;13(2):217-223.

41. Romanzini D, Ornaghi Junior HL, Amico SC, Zattera AJ. Preparation and Characterization of ramie-glass fiber reinforced polymer matrix hybrid composites. Materials Research. 2012;15(3):415-420.

42. Bevitori AB, Silva ILA, Simonassi N, Oliveira C, Margem FM, Monteiro SN. Tensile Behavior of Epoxy Composites Reinforced with Continuous and Aligned Ramie Fibers. In: Hwang JY, Bai C, Carpenter J, Ikhmayies SJ, Li B, Monteiro $\mathrm{SN}$, et al., eds. Characterization of Minerals, Metals and Materials 2013. Hoboken: Wiley; 2013 p. 465-472.

43. Oliveira C, Bevitori AB, Silva ILA, Margem FM, Altoe G, Faria Junior R, et al. Thermal Photoacoustic Characterization of Polyester Composites Reinforced Ramie Fibers. In: Hwang JY, Bai C, Carpenter J, Ikhmayies SJ, Li B, Monteiro SN, et al., eds. Characterization of Minerals, Metals and Materials 2014. Hoboken: Wiley; 2014. p. 507-514.

44. Callister WD Jr. Materials Science and Engineering - An Introduction. Hoboken: Wiley; 2007.

45. Garside P, Wyeth P. Identification of Cellulosic Fibres by FTIR Spectroscopy: Differentiation of Flax and Hemp by Polarized ATR FTIR. Studies in Conservation. 2006;51(3):205-211.

46. Bledzki AK, Gassan J. Composites reinforced with cellulose based fibres. Progress in Polymer Science. 1999;24(2):221-274.

47. Shah AN, Lakkad SC. Mechanical-properties of jute-reinforced plastics. Fibre Science \& Technology. 1981;15(1):41-46. 
48. Aquino R, D'Almeida JRM, Monteiro SN. Flexural mechanical properties of piassava fibers (Attalea funifera) - resin matrix composites. Journal of Materials Science Letters. 2001;20(11):1017-1019.

49. Yue C, Looi HC, Quek MY. Assessment of fiber-matrix adhesion and interfacial properties using the pull-out test. International Journal of Adhesion and Adhesives. 1995;15(2):73-80.

50. Dhakal HN, Zhang ZY, Richardson MOW, Errajhi OAZ. The low velocity impact response of non-woven hemp fibre reinforced unsaturated polyester composites. Composite Structures. 2007;81(4):559-567.

51. Monteiro SN, Costa LL, Lopes FPD, Terrones LAH. 2008. Characterization of the impact resistance of coir fiber reinforced polyester composites. In: Proceedings of TMS Conference; 2008 Mar; New Orleans, LA, USA.
52. de Farias MA, Farina MZ, Pezzin APT, Silva DAK. Unsaturated polyester composites reinforced with fiber and powder of peach palm: Mechanical characterization and water absorption profile. Materials Science \& Engineering: C. 2009;29(2):510-513.

53. Fu SY, Lauke B, Mäder E, Hu X, Yue CY. Fracture resistance of short-glass-fiber-reinforced and short-carbon-fiber-reinforced polypropylene under Charpy impact load and its dependence on processing. Journal of Materials Processing Technology. 1999;89-90:501-507.

54. Leão AL, Tan IH, Caraschi JC. Curaua fiber - a tropical natural fiber from Amazon - potential and applications in composites. In: Proccedings of the International Conference on Advanced Composites; 1998 May; Hurghada, Egypt. 